\title{
Morphological and physiological changes in Tetrahymena pyriformis for the in vitro cytotoxicity assessment of Triton X-100
}

\author{
Nicolina Dias ${ }^{\mathrm{a}}$, Renato A. Mortara ${ }^{\mathrm{b}}$, Nelson Lima ${ }^{\mathrm{a}, *}$ \\ ${ }^{a}$ Centro de Engenharia Biológica- IBQF, Universidade do Minho, Campus de Gualtar, 4710-057 Braga, Portugal \\ ${ }^{\mathrm{b}}$ Departamento de Microbiologia, Imunologia e Parasitologia, Escola Paulista de Medicina- UNIFESP, \\ Rua Botucatu, 862, 6. Andar, São Paulo, 04023, Brazil
}

Accepted 1 March 2003

\begin{abstract}
Non-ionic surfactants such as Triton X-100 have been widely used in industrial processing and in cleaning products for almost 50 years, being effective and economic emulsifying, wetting agents, dispersants and solubilizers. Cleaning products containing these surfactants are disposed of mainly by discharge into wastewater, which receives biological treatment in wastewater treatment systems. However, surface-active agents interact with eukaryotic cell membranes leading to biological damage at high concentrations. Tetrahymena pyriformis was used here as model organism to assess the effects of Triton X-100 through a series of in vitro cytotoxicity tests. Growth rates and morphological changes were, by their simplicity and reproducibility, the simplest toxicological assays. Cytoskeleton analysis seemed to be related with phagocytosis rate. Viability was evaluated by two different tests. Calcein AM/EthD-1 was used to assess T. pyriformis membrane damage during the 48-h experiment. The colorimetric MTT assay proved to be highly sensitive even at very short periods of Triton X-100 exposure. Tests performed in this study included simple and fast bioassays that provide overall information on the morphological and physiological state of cells exposed to different non-lytic and lytic concentrations of Triton X-100.
\end{abstract}

(C) 2003 Elsevier Science Ltd. All rights reserved.

Keywords: Cytotoxicity assessment; In vitro; Tetrahymena pyriformis; Triton X-100

\section{Introduction}

Ethylene oxide derivatives such as the non-ionic surfactant Triton X-100 have been widely used in industrial and household products due to their detergency, wetting and foaming properties, which give them an economic importance worldwide (Berthod et al., 2001).

Studies on haemolysis caused by non-ionic surfactants (Trägner and Csordas, 1987; Bielawski, 1990; Galembeck et al., 1998; Preté et al., 2002) have been useful to understand how the amphipathic molecule inserts into the bilayer membrane, leading to in vitro cytotoxicity

Abbreviations: BSA, bovine serum albumin; EthD-1, ethidium homodimer-1; DAPI, 4',6-diamidino-2-phenylindole; FDA, Fluorescein Diacetate; NBF, neutral buffered formalin; PBS, phosphate buffer saline; PPY, proteose peptone yeast extract medium.

* Corresponding author. Tel. +351-253604400; fax: +351253678986

E-mail address: nelson@iec.uminho.pt (N. Lima). assays for assessment of cell membrane damage. These techniques are being increasingly developed and evaluated as alternatives to the use of vertebrates in testing environmental pollutants. Besides the reduction of laboratory animals, these low cost tests allow the use of specific endpoints to determine the targets of toxic effects with great precision and reproducibility (Olabarrieta et al., 2001).

The cytotoxicity of several surfactants, including Triton X-100, was evaluated in different experimental model organisms such as Ehrlich ascites tumor and Chinese hamster lung cells (Szydlowska et al., 1978), dog red blood cells (Bean et al., 1991), rabbit cornea epithelial cells (Grant et al., 1992), and rat skeletal muscle cells (Gülden, 1993). Due to their sensitivity to environmental alterations protozoa have been proposed as biological indicators of water pollution (Nicolau et al., 1999). Moreover the simplicity of laboratory handling is an essential requirement to make these unicellular eukaryotes suitable as alternative organisms for aquatic 
toxicity evaluation of pollutants. Dryl and Mehr (1976) studied the physiological and toxic effects of some detergents on Paramecium caudatum. Besides the use of other protozoa as test-organisms, namely Colpidium campylum (Le Dû et al., 1993), Spirostomum ambiguum (Nalecz-Jawecki and Sawicki, 2002) and Spirostomum teres (Madoni et al., 1992; Madoni and Davoli, 1994; Twagilimana et al., 1998), Tetrahymena pyriformis is one of the most commonly used ciliated protozoa for laboratory research. In this ciliate various endpoints can be used to evaluate the cytotoxic effects of xenobiotics (Sauvant et al., 1999). Growth rate and morphological changes (Meyer et al., 1971; Sauvant et al., 1994; Schäfer et al., 1994; Larsen et al., 1997; Kovács et al., 1999; Nilsson, 1999) have been used for some decades. Population growth impairment is an often-used sublethal toxic endpoint for organic (Larsen et al., 1997) and inorganic (Sauvant et al., 2000) compounds, which does not require special technical expertise (Nicolau et al., 1999). Other parameters such as cell motility (Wu et al., 1997; Gräf et al., 1998/99; Darcy et al., 2002) and swimming patterns (Noever et al., 1994), cytoskeleton analysis (Dias et al., 1998; Kovács and Csaba, 1998; Casalou et al., 2001), phagocytosis rate (Nilsson, 1974; Nilsson, 1981; Stefanidou et al., 1990; Darvas et al., 1999; Stefanidou et al., 1999), can be assessed and have been proposed to determine the physiological and energetic state of $T$. pyriformis when in contact with pollutants. The MTT assay, which determines dehydrogenase activity, is performed in 96-well microplates and allows a rapid and low cost screening of different agents at various concentrations simultaneously. It does not require the technical expertise of some of the standardized bioassays (Dias et al., 1999).

In this work, Tetrahymena pyriformis was used as a model organism to assess the effects of the non-ionic surfactant Triton X-100 through an in vitro series of cytotoxicity tests. The tests performed in this study included simple and fast bioassays that give overall information about the morphological and physiological state of the cells exposed to different non-lytic and lytic concentrations of Triton X-100.

\section{Material and methods}

\subsection{Cell cultures and surfactant exposure}

All toxicological assays used axenic 18-24 h cultures of Tetrahymena pyriformis strain GL, ref. CCAP/1630/ $1 \mathrm{~F}$ from Strains of Culture Collection of Algae and Protozoa, UK. The cells were grown to exponential phase at room temperature in Proteose Peptone Yeast Extract Medium (PPY), 2\% proteose peptone and $0.25 \%$ yeast extract at $\mathrm{pH} 7.0-7.5$. The density of T. pyriformis cultures was adjusted in fresh PPY in order to obtain at least $10^{4}$ cells $/ \mathrm{ml}$. Triton X-100 (octylphenoxypolyethoxyethanol, Merck) was added to the cells at $0.01,0.05$, and $0.1 \mathrm{mg} / \mathrm{ml}$ and non-exposed cells to the surfactant were used as control. Untreated and treated $T$. pyriformis were incubated in $2-\mathrm{ml}$ Eppendorf tubes in a total volume of $1.5 \mathrm{ml}$. In order to confirm that the small volume of the test-tubes did not induce poor oxygenated conditions to the cells, two assays were performed: a total culture volume of $1.5 \mathrm{ml}$ was used in 2-ml Eppendorf tubes and in 12-ml plastic test tubes. A high correlation $\left(r^{2}=0.989\right)$ of growth rate was obtained in these two assays. Samples from two independent assays were taken at $0.1,1,24$ and $48 \mathrm{~h}$.

\subsection{Population growth impairment and generation time determination}

Aliquots of $100 \mu 1$ were immediately taken $\left(T_{\mathrm{o}}\right)$ from the control and the exposed cultures, and subsequently at 24 and $48 \mathrm{~h}$. The samples were properly diluted in distilled water and fixed with Neutral Buffered Formalin (NBF) containing, $10 \%(\mathrm{v} / \mathrm{v})$ formalin in phosphate buffer saline (PBS) $\mathrm{pH} 7.0$ at a final concentration of $2-5 \%$, for $1 \mathrm{~h}$. The cell number was determined by counting every cell present in each of two $30 \mu \mathrm{l}$ subsamples with an inverted optical microscope (Nikon Diaphot 300) at $100 \times$ magnification. The Tetrahymena populations were characterized by their generation time $(g)$ required for doubling the population. Generation time was calculated by the following formulas (1), (2).

number of generations $(n)$

$n=\frac{\log N_{1}-\log N_{0}}{\log 2}$

$\underline{\text { Generation time }(g)}$

$g=\frac{\text { Time of growth }}{\text { Number of generations }}$

Where $N_{1}$ is the number of cells at $24 \mathrm{~h}, N_{\mathrm{o}}$ is the number of cells at $T_{\mathrm{o}}$; Time of growth $=24 \mathrm{~h}$.

\subsection{Immunocytochemistry}

\subsubsection{Antibodies}

Rabbit monoclonal antibody to actin; mouse ascites fluid monoclonal antibody to Amoeba actin (clone KJ43A), mouse ascites fluid monoclonal antibody to acetylated $\alpha$-tubulin (clone 6-11B-1), anti-rabbit IgG (Fab specific) FITC conjugated, anti-mouse IgG (Fab specific) FITC conjugated, and anti-mouse IgG (whole molecule) $\mathrm{Cy} 3$ conjugate were all purchased from Sigma-Aldrich, Germany. Storage and handling of antibodies were performed as recommended by the supplier. 


\subsubsection{Indirect immunofluorescence}

After treatment with Triton X-100 cells were concentrated by centrifugation at $5000 \mathrm{rpm}$ for $5 \mathrm{~min}$ and the supernatant was discarded. Cells were fixed with $\mathrm{NBF}$, for $1 \mathrm{~h}$. The fixed cells were centrifuged at 1300 $\mathrm{rpm}$ for $1 \mathrm{~min}$ and aliquots from the pellet $(50 \mu \mathrm{l})$ were transferred into Eppendorf tubes and resuspended in fresh $0.1 \%(\mathrm{w} / \mathrm{v})$ sodium azide (Merck) in PBS. Cells were allowed to settle and dry on an 8 well glass slide previously covered with a solution of $0.01 \%(\mathrm{w} / \mathrm{v})$ polyL-lysine (Sigma-Aldrich) in PBS. Cells were rehydrated, permeabilized and blocked with $0.1 \%(\mathrm{w} / \mathrm{v})$ saponin, $0.25 \%(\mathrm{w} / \mathrm{v})$ gelatin in PBS (PGN) for $15 \mathrm{~min}$. After two washes in PBS the cells were incubated overnight at $4{ }^{\circ} \mathrm{C}$ with either anti-actin monoclonal antibody diluted $1: 400$ or anti-acetylated $\alpha$-tubulin monoclonal antibody diluted 1:200 in a humid chamber. Antibody dilutions were made with PGN solution. Cells were then washed twice with PGN and incubated with the secondary antimouse IgG FITC conjugated antibody diluted 1:50 for $45 \mathrm{~min}$ at room temperature. After labeling, cells were washed with PGN. For negative control experiments, primary antibody was replaced with $3 \%(\mathrm{w} / \mathrm{v})$ bovine serum albumin (BSA, Sigma-Aldrich) in PBS. A drop (15 $\mu \mathrm{l}$ ) of $10 \mu \mathrm{g} / \mathrm{ml} \quad 4^{\prime}, 6$-diamidino-2-phenylindole (DAPI, Sigma-Aldrich) was added before mounting. Slides were mounted with Fluoromount G (Southern Biotechnology Associates) and analyzed with an inverted optical microscope (Zeiss Axiovert 100 with a $40 \times 1.2$ water immersion PlanApochromatic objective) attached to a Bio-Rad MRC 1024UV laser scanning confocal fluorescence system. Images were acquired by Kalman averaging at least 10 times a $512 \times 512$ pixel frame, using a pinhole not larger than $2 \mathrm{~mm}$.

\subsubsection{Double immunofluorescence}

For double immunostaining, fixed and washed cells (see above) were incubated overnight at $4{ }^{\circ} \mathrm{C}$ with antiactin antibody (developed in rabbit, 1:200) and then washed twice in PGN. Cells were then labeled with antirabbit IgG FITC conjugated antibody diluted 1:20 for $45 \mathrm{~min}$ at room temperature and washed again with PGN. In order to localize cilia, samples were then incubated with anti-acetylated $\alpha$-tubulin monoclonal antibody (developed in mouse, 1:200), at room temperature for $1 \mathrm{~h}$. After washing twice in PGN cells were incubated in anti-mouse $\operatorname{IgG} \mathrm{Cy} 3$ conjugated antibody (1:200) for $45 \mathrm{~min}$ at room temperature. Cells were then washed twice in PGN and mounted as described above.

\subsection{Calcein $A M /$ EthD-1 viability assay}

Cells were labelled with freshly prepared solutions from the LIVE/DEAD ${ }^{\circledR}$ Viability/Cytotoxicity Assay Kit (Molecular Probes Europe, BV) at final concentrations of $10 \mu \mathrm{M}$ calcein AM $\left[4^{\prime} 5^{\prime}\right.$-bis $\left(N^{\prime} N^{\prime}\right.$-bis (carboxymethyl) aminomethyl fluorescein acetoxymethyl ester)] and 2.5 $\mu \mathrm{M}$ EthD-1 (ethidium homodimer-1) in PBS. No cytotoxic effects of calcein AM and no protozoan autofluorescence were observed under the experimental conditions. Storage and handling of reagents were performed as recommended by the supplier. The cytotoxicity and recovery assay procedures were performed according to Dias and Lima (2002).

\subsection{MTT assay}

A volume of $80 \mu$ of suspended $T$. pyriformis was added to each well of a 96-well flat-bottom microtiter plate. Ten microliters of MTT (3-(4,5-dimethyl-tiazol-2yl)-2,5 diphenyl-tetrazolium bromide (Sigma) stock solution $(10 \mathrm{mg} / \mathrm{ml}$ in distilled water) were added and the plates were incubated at $25^{\circ} \mathrm{C}$ for $4 \mathrm{~h}$. The MTT reduction was stopped with $210 \mu \mathrm{l}$ of a solution containing $50 \%$ dimethylformamide $(\mathrm{M} \& \mathrm{~B})$ and $10 \%$ sodium dodecyl sulfate $(\mathrm{BDH})-(\mathrm{DMF} / \mathrm{SDS})$ without removing the medium. An ELISA spectrophotometric microplate reader (SLT SPECTRA 1) was used for measuring the formazan production due to dehydrogenase activity at $550 \mathrm{~nm}, 30 \mathrm{~min}$ after DMF/SDS incubation. Two wells containing PPY medium without cells were used to assess the background levels of absorbance. These blank values were subtracted from the absorbance values of the experimental samples.

\subsection{Morphometric analysis}

Treated and non-treated samples were fixed for $1 \mathrm{~h}$ in NBF solution, washed and stained with $0.01 \%$ toluidin blue (Sigma). A drop of suspended culture was added onto microscopic slides and was analyzed with an inverted optical microscope (Nikon Diaphot 300) at $100 \times$ magnification. Images were taken with a CCD monochrome video camera (Sony AVCD5CE), binarized and the data analyzed by the MATLAB 5.1 software package (The Mathworks Inc., Natick) in order to determine area and ratio $(\mathrm{W} / \mathrm{L})$ of the shortest $(\mathrm{W})$ and the longest (L) axis of cells. The morphological parameters were then determined from the final binary image. A previous calibration was performed through a slide engraved with a grid-ruler fitted to $1 \mathrm{~mm}$. At $100 \times$ magnification, $0.5 \mathrm{~mm}$ corresponded to an average value of 459 pixels in the computer screen. Following the same conditions for image capture, the pixel to $\mu \mathrm{m}$ ratio was calculated following the equation: 1 pixel $=1.089 \mu \mathrm{m}$. In each sub-sample 100 randomly cells were analyzed.

\subsection{Grazing assay}

The assay was performed in 2-ml Eppendorf test tubes, by adding yellow-green fluorescent latex Fluorospheres 
(0.5 $\mu \mathrm{m}$ diameter, Molecular Probes Europe BV) both to treated and control cells, considering that ciliates have no prey selection in their feeding process (Fenchel, 1980). A final concentration of $\pm 1.05 \times 10^{6}$ beads $/ \mathrm{ml}$ in PPY medium was used according to Nicolau et al. (1999). After 20 min of incubation in the dark, samples were killed and fixed by the addition of NBF solution for $1 \mathrm{~h}$. Cells were then washed and resuspended in fresh $0.1 \%(\mathrm{w} / \mathrm{v})$ sodium azide in PBS and stored in the dark until subsequent analysis with an epifluorescence microscope (Leitz Laborlux S) at UV light (EX 450-490 $\mathrm{nm}$ excitation filter). The number of beads ingested by individual cells was counted at a magnification of $1000 \times$. In each sub-sample 50 randomly cells were analyzed.

\subsection{Statistical data analysis}

In each assay, the experimental data represent the mean of two independent assays. ANOVA test was used for significance calculations of growth and grazing tests calculations Student $t$-test was used in morphometry, calcein AM/EthD- 1 and MTT tests. $P<0.05$ and $P<0.01$ were accepted as levels of statistical significance between groups.

\section{Results}

\subsection{Population growth impairment and generation time determination}

In our culture conditions, the cell density at the beginning of the experiment $\left(T_{0}\right)$ was $1.3 \times 10^{4}$ cells $/ \mathrm{ml}$ and the normal generation time of $T$. pyriformis was about $7.3 \mathrm{~h}$. Addition of Triton X-100 affected growth (Fig. 1) and generation time (Table 1) in a dose-dependent manner. The lower surfactant concentration $(0.01$ $\mathrm{mg} / \mathrm{ml})$ did not cause significant decrease $(P<0.05)$ in $T$. pyriformis growth. However growth decreased above the intermediate $(0.05 \mathrm{mg} / \mathrm{ml})$ Triton X-100 concentrations since after $24 \mathrm{~h}$ of exposure, most cells were no longer able to divide (Fig. 1).

Some recovery assays were performed to ensure that cells could recovery their normal morphology and growth ability after the 1-min Triton X-100 exposure. Results from previous studies (Dias and Lima 2002) demonstrate that $T$. pyriformis is able to recover normal shape and its capacity to divide even after exposure to the higher Triton X-100 concentration $(0.1 \mathrm{mg} / \mathrm{ml})$.

\subsection{Cytoskeletal alterations in Triton $X$-100 treated cells}

The mouse anti-actin monoclonal antibody was used to localize actin and disclose its distribution in Tetrahymena pyriformis, revealing the microfilament architecture. In

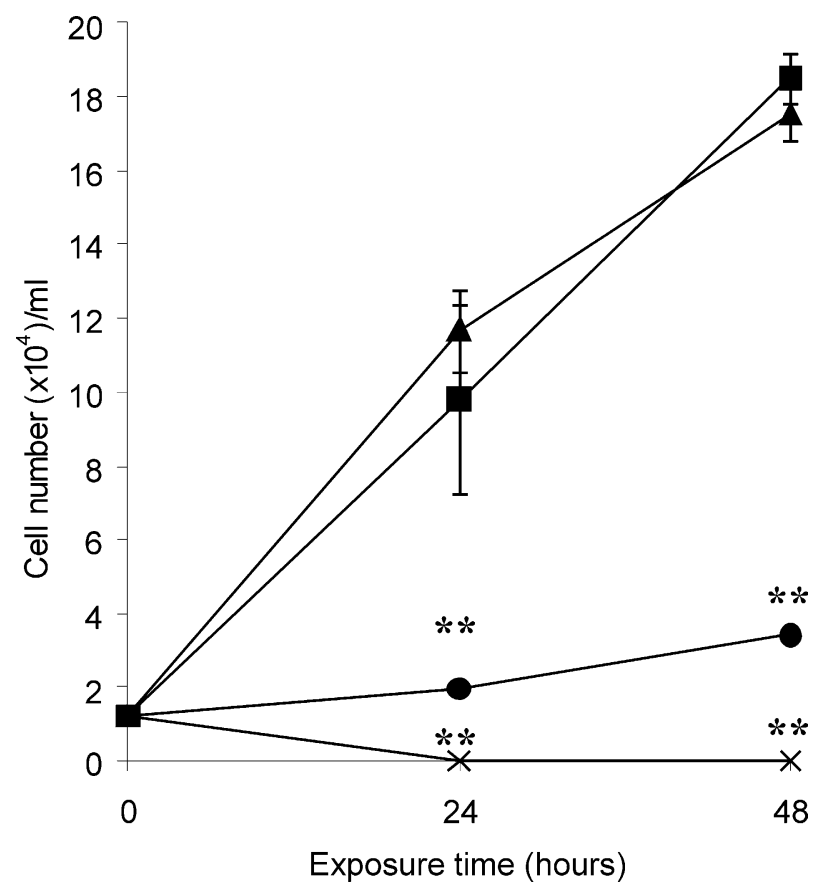

Fig. 1. Effect of Triton X-100 on T. pyriformis population growth in a 48 h-experiment. Concentrations used were: control $(\boldsymbol{\Delta}), 0.01 \mathrm{mg} / \mathrm{ml}$ $(\boldsymbol{\square}), 0.05 \mathrm{mg} / \mathrm{ml}(\mathbf{O})$ and $0.1 \mathrm{mg} / \mathrm{ml}(\mathbf{x})$. Data are mean of two independent assays and bars represent standard deviations. ${ }^{* *}$ Indicates significant differences from control values $(P<0.01)$.

Table 1

Effect of Triton X-100 on T. pyriformis generation time after $24 \mathrm{~h}$ of growth

\begin{tabular}{ll}
\hline Triton X-100 concentrations $(\mathrm{mg} / \mathrm{ml})$ & Generation time $(\mathrm{h})$ \\
\hline Control & $7.35 \pm 0.02$ \\
0.01 & $7.99 \pm 0.64$ \\
0.05 & $35.3 \pm 1.43^{* *}$ \\
0.1 & - \\
\hline
\end{tabular}

Each value is the mean of two independent assays \pm standard deviation.

** Indicates significant differences from control values $(P<0.01)$.

control cells actin was visualized as bright fluorescent longitudinal rows underneath the cell surface and strong labeling was also observed on the ciliated oral apparatus (Fig. 2A). Acetylated $\alpha$-tubulin decorated cilia on longitudinal arrays along the cell's surface and bright fluorescence was observed on the oral apparatus indicating the presence of numerous cilia in this structure (Fig. 2B).

Changes in the microfilament network were observed during the $24 \mathrm{~h}$ period of Triton X-100 treatment at 0.05 $\mathrm{mg} / \mathrm{ml}$ (Fig. 3). Very early $(0.1 \mathrm{~h})$, lack of fluorescence on the oral apparatus of most cells seemed to indicate the redistribution of actin due to the surfactant exposure (Fig. 3A). After $1 \mathrm{~h}$ of treatment a large unstained area in the central part of the cytoplasm was observed (Fig. 3B). From this time cells started to round and the nucleus moved to the cell periphery (Fig. 3C). 

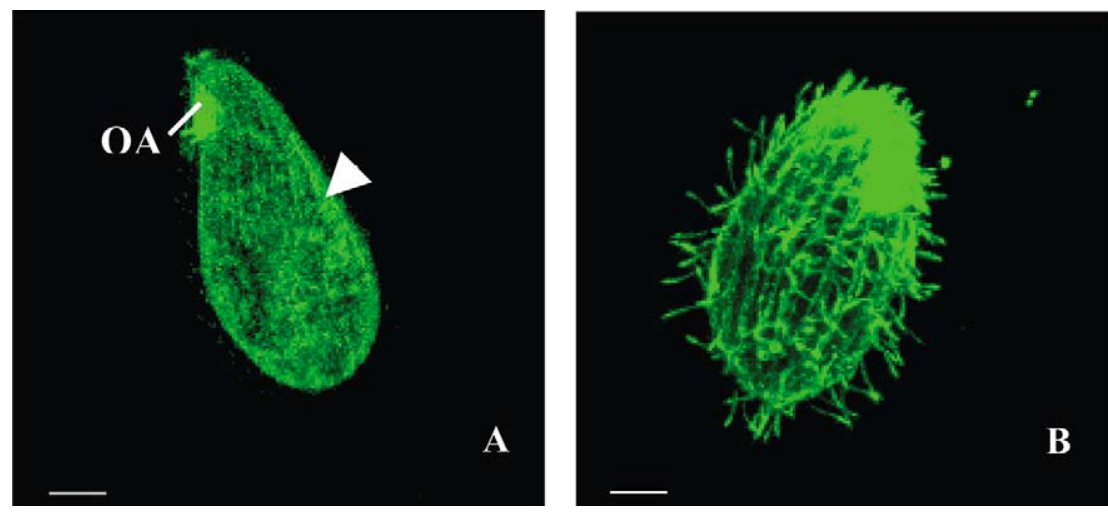

Fig. 2. Confocal fluorescence microscopy images of untreated (control) T. pyriformis labelled with anti-actin monoclonal antibody and anti-mouse IgG-FITC conjugate (A) and with anti-acetylated- $\alpha$-tubulin monoclonal antibody and anti-mouse IgG-FITC conjugate (B). Bright fluorescent longitudinal rows underneath the cell surface (arrowhead) and the ciliated oral apparatus (OA) show intense fluorescence labelling. Bar $=10 \mu \mathrm{m}$.
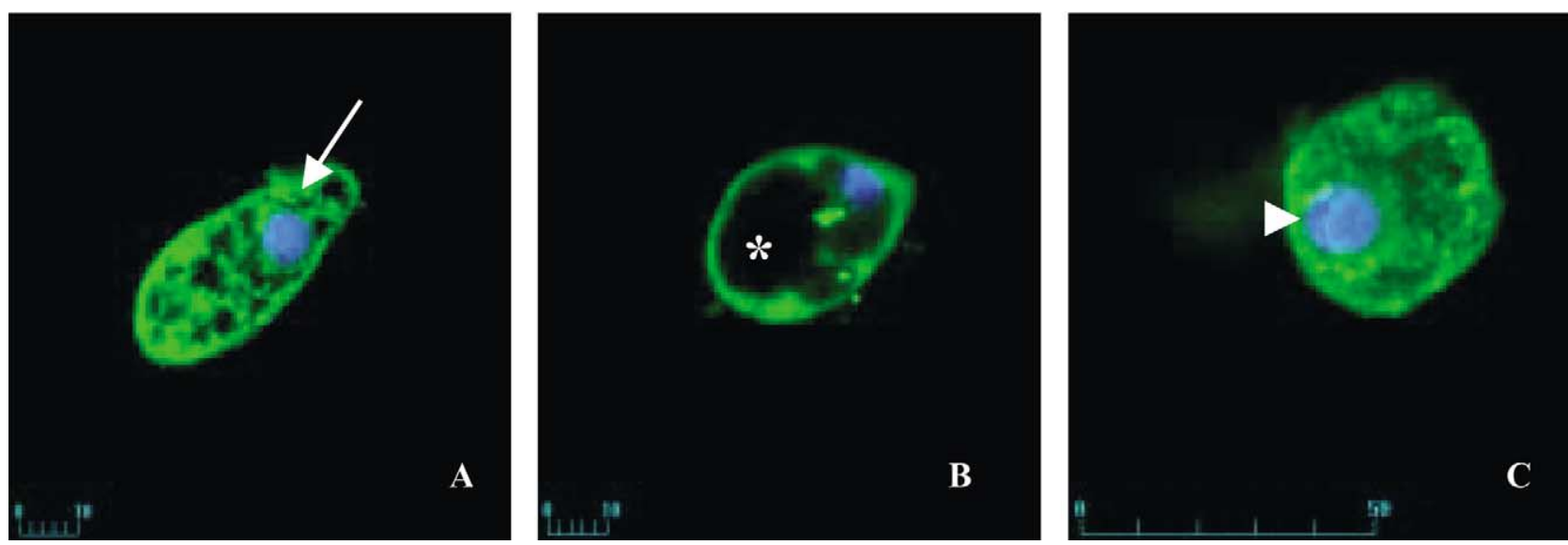

Fig. 3. Confocal fluorescence microscopy images of Triton X-100 $(0.05 \mathrm{mg} / \mathrm{ml})$ treated culture of T. pyriformis labelled with anti-actin monoclonal antibody and anti-mouse IgG-FITC conjugate (green), after $0.1 \mathrm{~h} \mathrm{(A),} 1 \mathrm{~h} \mathrm{(B)}$ and $24 \mathrm{~h} \mathrm{(C)}$ of exposure. The oral apparatus shows a decrease of fluorescence labelling (arrow). Large organelle-free area appeared in $1 \mathrm{~h}$ - treated cells (asterisk). Nucleus (labeled with DAPI, in blue) moved to the cell periphery (arrowhead). Bar, $\mu \mathrm{m}$ as shown.

Double immunofluorescence was used to observe simultaneously the effect of Triton X-100 on the ciliary system and on the actin network. Red strong labeling in control cells indicates the presence of numerous cilia along the surface body and in the oral apparatus (Fig. 4A, B). In contrast, the 1-h treated cells show lost of cilia mostly in Tetrahymena's body but also in oral apparatus (Fig. 4C, D). Yellow labeling, which was only observed in control cells (Fig. 4A) indicates co-localization of actin and acetylated $\alpha$-tubulin.

\subsection{Calcein AM/EthD-1 viability assay}

A major feature of the cytotoxicity assay using calcein $\mathrm{AM} / \mathrm{EthD}-1$ is the ability to distinguish two different populations within the same sample. Intracellular esterases of living cells convert the non-fluorescent cell permeant calcein AM to the green $(530 \mathrm{~nm})$ fluorescent calcein, which is retained in viable cells. The addition of EthD-1, which binds to DNA, stained nuclei of dead cells in red. A dose-dependence on Triton X-100 concentration was observed (Fig. 5), since an increase in surfactant concentration led to a decrease in $T$. pyriformis viability; although at earlier times of Triton $\mathrm{X}-100$ exposure no significant viability alterations were found, even at the highest detergent concentration. An exposure of at least $24 \mathrm{~h}$ to the lowest surfactant concentration did not significantly alter cell viability. However, at the same exposure time, treatment with 0.05 and $0.1 \mathrm{mg} / \mathrm{ml}$ of Triton X-100 resulted in a highly significant decrease $(P<0.01)$ of $T$. pyriformis viability. At the highest surfactant concentration, Triton X-100 displayed a time-dependent effect and significantly influenced the ciliate's viability after $1 \mathrm{~h}$ of treatment.

\subsection{MTT assay}

Treatment with Triton X-100 concentrations above $0.05 \mathrm{mg} / \mathrm{ml}$ caused a highly significant $(P<0.01)$ decrease in MTT reduction, even at short periods $(1 \mathrm{~h})$ of treatment (Fig. 6). Earlier already $(0.1 \mathrm{~h})$ and at the 

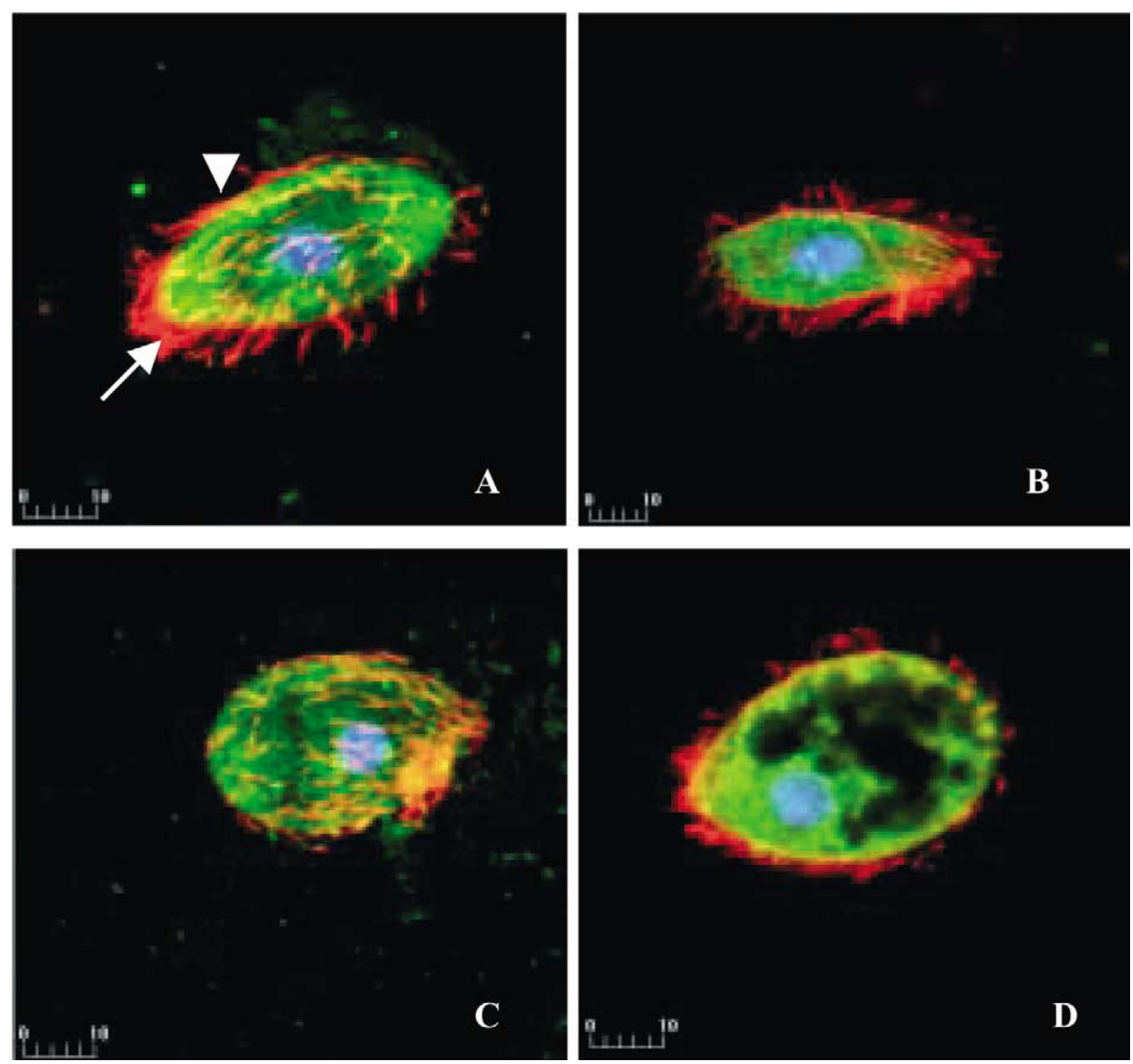

Fig. 4. Confocal fluorescence microscopy of control (A, B) and Triton X-100 (0.05 mg/ml) (C, D) treated of T. pyriformis labelled with anti-actin monoclonal antibody and anti-acetylated $\alpha$-tubulin monoclonal antibody, stained with anti-rabbit IgG-FITC conjugate (green) and anti-mouse IgG Cy3 conjugate (red), respectively. Images were acquired at a surface focal plane (A, C) and at the nuclear level (after DAPI labeling in blue, B, D). Oral apparatus (arrow) and cilia (arrowhead) were clearly visualized in control cells. Bar, $\mu \mathrm{m}$ as shown.

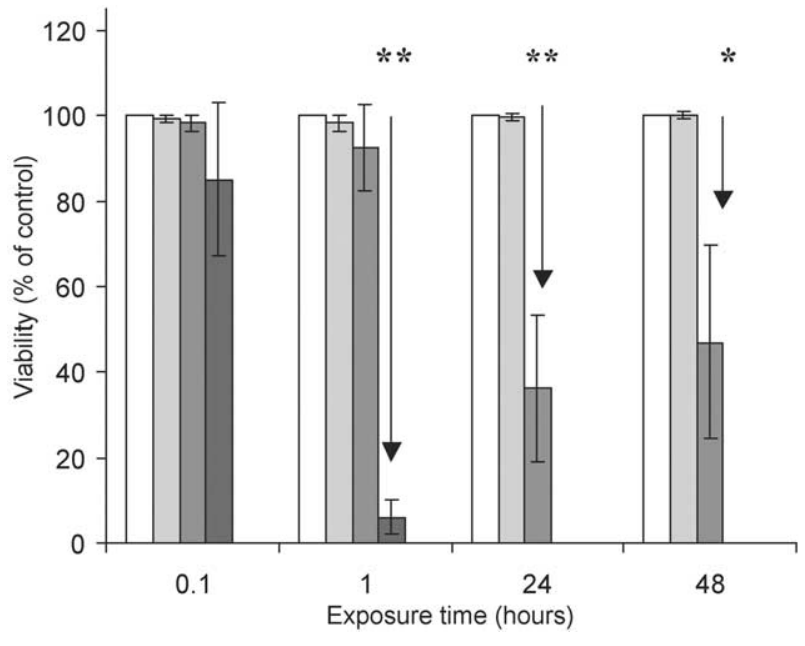

Fig. 5. Effect of Triton X-100 on the viability of T. pyriformis in a 48 h-experiment expressed by the Calcein $\mathrm{AM} / \mathrm{EthD}-1$ assay. Concentrations used were: control $\square, 0.01 \mathrm{mg} / \mathrm{ml} \square, 0.05 \mathrm{mg} / \mathrm{ml} \square$ and $0.1 \mathrm{mg} /$ $\mathrm{ml} \square$. Data expressed relative to mean values in respective untreated controls in two independent assays. Bars represent standard deviations. * Indicates significant differences from control values $(P<0.05)$. ** Indicates significant differences from control values $(P<0.01)$.

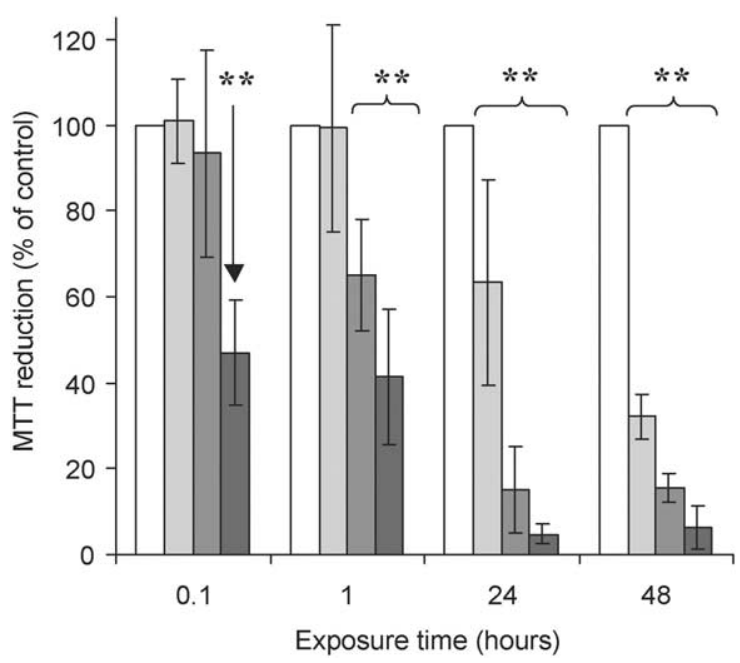

Fig. 6. Effect of Triton X-100 on the MTT reduction in T. pyriformis in a 48 h-experiment. Data expressed relative to mean values in respective untreated controls in three independent assays. Concentrations used were: control $\square, 0.01 \mathrm{mg} / \mathrm{ml}, \square 0.05 \mathrm{mg} / \mathrm{ml} \square$ and $0.1 \mathrm{mg}$ / $\mathrm{ml} \square$. Bars represent standard deviations. ** Indicates significant differences from control values $(P<0.01)$. 
highest $(0.1 \mathrm{mg} / \mathrm{ml})$ surfactant concentration a decrease of about $50 \%$ of dehydrogenase activity was observed. These results show a dose-dependent response of Triton $\mathrm{X}-100$. The decrease in viability was significant above 24 $\mathrm{h}$, of all Triton X-100 concentrations, even to $0.01 \mathrm{mg} /$ ml-exposed cells.

\subsection{Morphometric analysis}

Triton X-100 effects were also observed in morphometric features of the cells. The results of two independent assays on cell area and ratio (W/L) are shown (Fig. 7A and B). The lowest surfactant concentration did not cause significant differences in cell area except after the longest treatment period $(48 \mathrm{~h})$. Nevertheless, above $0.05 \mathrm{mg} / \mathrm{ml}$ Triton X-100 significantly influenced both area and $\mathrm{W} / \mathrm{L}$ ratio during the complete experiment period. Therefore, cell size decrease and $\mathrm{W} / \mathrm{L}$ ratio increase suggested rounding off of the cells. These results corroborate the visualization of the distribution of cytoskeletal proteins during the immunocytochemical studies (see Fig. 3B and C).

\subsection{Grazing assay}

The effects of Triton X-100 on grazing capacity of T. pyriformis are shown in Fig. 8. The surfactant above $0.05 \mathrm{mg} / \mathrm{ml}$, reduced cell ingestion capability to less than $5 \%$, only few minutes after the contact. Nevertheless, after $24 \mathrm{~h}$-treatment the inhibition was only $20 \%$ of the controls, showing an increase in Tetrahymena grazing capacity. That might suggest cells recover from Triton $\mathrm{X}-100$ injury. At the highest $(0.1 \mathrm{mg} / \mathrm{ml})$ concentration, Triton X-100 completely inhibited bead ingestion.

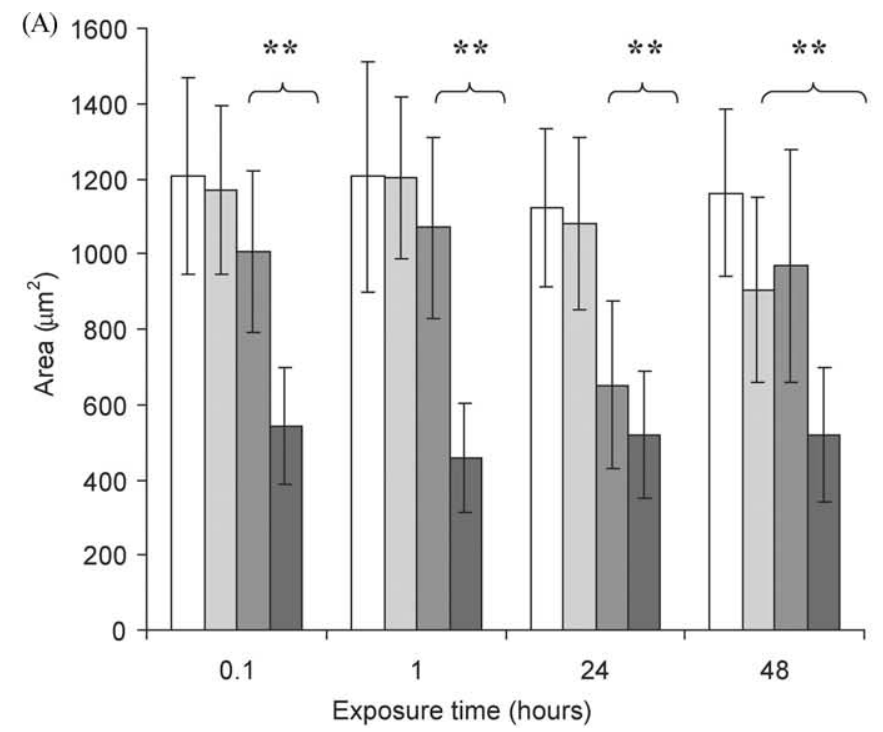

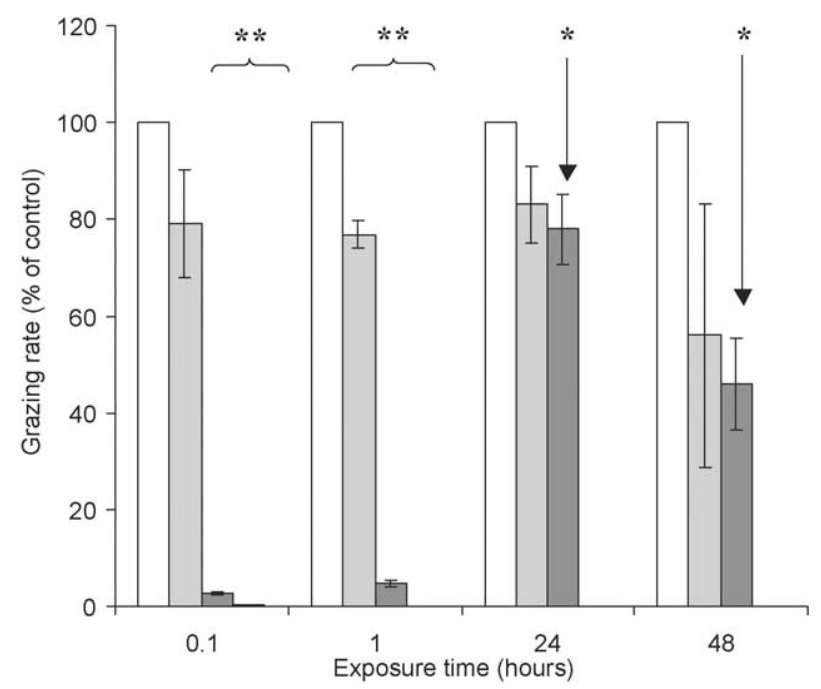

Fig. 8. Effect of Triton X-100 on the grazing capacity of T. pyriformis. Data are expressed relative to mean values of untreated controls in two independent assays. Concentrations used were: control $\square, 0.01$ $\mathrm{mg} / \mathrm{ml} \square, 0.05 \mathrm{mg} / \mathrm{ml} \square$ and $0.1 \mathrm{mg} / \mathrm{ml} \square$. Bars represent standard deviations. * Indicates significant differences from control values $(P<0.05) .{ }^{* *}$ Indicates significant differences from control values $(P<0.01)$

\section{Discussion}

Bioassays and model systems are currently used in ecotoxicology providing information for risk evaluation of new chemicals and leading to the investigation of their effects and mechanisms of action. In this work, six bioassays were used to determine the cytotoxicity of a non-ionic surfactant, Triton X-100, on Tetrahymena pyriformis as a model organism.

(B)

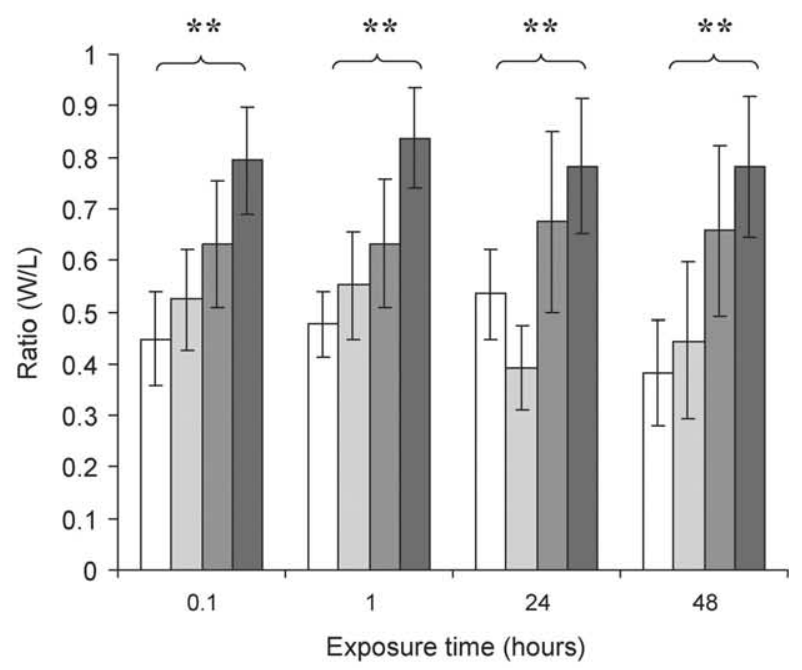

Fig. 7. Effect of Triton X-100 on the size (area) (A) and the ratio of shortest and longest axis (W/L) (B) of T. pyriformis. Data expressed relative to mean values of untreated controls in two independent assays. Concentrations used were: control $\square, 0.01 \mathrm{mg} / \mathrm{ml} \square, 0.05 \mathrm{mg} / \mathrm{ml} \square \mathrm{and} 0.1 \mathrm{mg} / \mathrm{ml} \square$. Bars represent standard deviations. ** Indicates significant differences from control values $(P<0.01)$. 
Immunolabeling of cells with antibodies against cytoskeletal main proteins, such as actin and acetylated $\alpha$-tubulin, provides visualization of cell cytoskeleton alterations after surfactant exposure. Actin polimerization is a critical process for eukaryotic cell motility (Schafer et al., 1998). Moreover, intracellular movements, cell division and maintenance of cell shape also depend on the rapid conversion between monomeric $(\mathrm{G})$ and filamentous actin (Cooper, 1991). Therefore, it appeared that actin filaments are also involved in food vacuole processes (Méténier, 1984) and the normal function of the osmoregulatory system (Kovács and Csaba, 1998). The lack of actin and acetylated $\alpha$-tubulin on the oral apparatus, at higher surfactant concentrations $(0.05$ and $0.1 \mathrm{mg} / \mathrm{ml})$, was clearly visualized at earlier time of exposure $(0.1 \mathrm{~h})$. These results could explain the lack of grazing capacity showed by the predation assay, since a highly significant $(P<0.01)$ decrease in ingestion capability was also observed at earlier time of Triton X-100 exposure $(0.1 \mathrm{~h})$.

The relationship between actin and osmoregulation seemed to be in accordance with the observed actin redistribution in Triton X-100 $(0.05 \mathrm{mg} / \mathrm{ml})$ treated cells after $1 \mathrm{~h}$ of the surfactant treatment. This concentration might cause cell swelling as a result of an unbalanced osmoregulation process, without membrane damaging, at short exposure time ( 0.1 to $1 \mathrm{~h})$. Under those experimental conditions, if cells maintain membrane integrity despite their altered shape, no significant differences relative to the control were to expect in the Calcein AM/ EthD-1 test. Furthermore the recovery assay showed that $T$. pyriformis was able to recover the normal shape and its capacity to divide, suggesting cell viability. It has been already proved that esterase activity is a good test for measuring viability in membrane-injured cells (Nicolau et al., 2001; Dias and Lima, 2002). Our results are in agreement of Bogaerts et al. (2001) who used another fluorogenic derivative fluorescein diacetate in $T$. pyriformis and found a higher sensitivity of this assay compared to other ones. The main advantage of these enzymatic assays is that they offer new possibilities to use advanced data analysis and quantification techniques to assess cytotoxicity in protozoa (Dias and Lima, 2002). MTT is another test that evaluates cell viability through enzymatic activity. The MTT test was more sensitive than the Calcein AM/EthD-1 test for very short periods of Triton X-100 exposure $(0.1 \mathrm{~h})$, since significant $(P<0.01)$ values were found for the highest detergent concentration $(0.1 \mathrm{mg} / \mathrm{ml})$. Furthermore, after a longer treatment $(24 \mathrm{~h})$ a decrease in viability with $40 \%$ was observed at the lowest $(0.01 \mathrm{mg} / \mathrm{ml})$ Triton X-100 concentration. On the other hand, although only $6 \%$ of the cells were still viable after $1 \mathrm{~h}$ Triton X-100 exposure $(0.1$ $\mathrm{mg} / \mathrm{ml}$ ) with the Calcein AM/EthD-1 assay, about $40 \%$ were able to produce formazan. This suggests that some mitochondrial dehydrogenase activity remains even after almost all cells were lethally damaged. These results are in agreement with those of Martin and Clynes (1993) who found some mitochondrial activity in two-day damaged cells. More than two decades ago Gurtubay et al. (1980) already investigated several mitochondrial inner-membrane enzyme activities and showed that, although some functional complexes seemed to be disrupted by the surfactant, the activity of individual enzymes was preserved. Although values between control and lowest surfactant concentration $(0.01 \mathrm{mg} / \mathrm{ml})$ were not statistically significant in the first hour of treatment, a higher absorbance might indicate an increase in cell viability. In fact, Stowe et al. (1995) stated that Triton X-100 at slightly toxic concentrations stabilizes and disperses effectively the formazan microemulsion, inducing higher absorbance values.

Besides the possible actin microfilament-disturbing effect of Triton X-100 the rounding off of T. pyriformis is a sign of prospective death (Kovács et al., 1999). After an exposure time more than $24 \mathrm{~h}$ at higher Triton X-100 concentrations $(0.05$ and $0.1 \mathrm{mg} / \mathrm{ml})$ a high percentage of cells showed a lack in membrane integrity affecting their viability. Ectoplasmic contraction during exposure of Paramecium caudatum to various detergents was observed by Dryl and Mehr (1976). In this study the authors reported that morphological changes as the degree of shortening of body shape depends on the concentration of the surfactant, being more strongly expressed in their higher concentrations. In our work morphological alterations such as in the area and ratio W/L were also observed. Morphometric analysis is suitable with lytic agents that alter significantly the cell's shape.

Triton X-100 is often regarding as a "mild" surfactant (Le Maire et al., 2000). It is a non-denaturating surfactant, but a very good lytic surfactant. Bielawski (1990) reported that a range of Triton X-100 between 0.003 to $0.008 \%$ (i.e. $0.03 \mathrm{mg} / \mathrm{ml}$ to $0.08 \mathrm{mg} / \mathrm{ml}$ ) causes swelling followed by hemolysis of erythrocytes. In this work similar ranges of concentration of the surfactant were used and lytic concentrations were found at the range of 0.05 to $0.1 \mathrm{mg} / \mathrm{ml}$. Helistö and Koorpela (1998) have also reported that around CMC concentration $(0.014 \%)$ (i.e. $0.14 \mathrm{mg} / \mathrm{ml}$ ) of Triton X-100 eukaryotic lipases were inhibited $60-80 \%$. It was found in our work that $0.1 \mathrm{mg} / \mathrm{ml}$ of Triton X-100 also inhibited T. pyriformis esterase's. Short-term effects within 0.1 to $1 \mathrm{~h}$ were detected by all tests above $0.05 \mathrm{mg} / \mathrm{ml}$-exposed cells. However for very low Triton X-100 concentration (0.01 $\mathrm{mg} / \mathrm{ml}$ ), MTT was the only test able to detect change in enzymatic activities. That might suggest long-term effect of the surfactant in Tetrahymena dehydrogenases.

In toxicological studies a single bioassay cannot provide the full picture of the effects in an organism. Hence, we proposed a novel approach, using a battery of representative toxicological tests. Morphological, structural, 
physiological and biochemical assays were used to provide global information for cytotoxicity of a widely used detergent on the ciliate $T$. pyriformis. Finally, we expect that this combination of assays might represent a sensitive way of testing for similar types of agents as well as their possible effects on target systems of a variety of organisms.

\section{Acknowledgements}

The authors thank L. Amaral (Centro de Engenharia Biologica, Universidade do Minho, Braga) for his collaboration in the use of the image analysis software for the morphometric assay. The authors acknowledge the financial support provided by the Instituto de Biotecnologia e Química Fina (IBQF). Nicolina Dias was supported by grant PRAXIS XXI/BD/20328/99 from FCT-Portugal. The support of the Brazilian agencies FAPESP and CNPq to RAM is also acknowledged.

\section{References}

Bean, C.L., Galloway, S.M., Bradley, M.O., 1991. Evaluation of three in vitro assays for assessment of membrane damage by surfactants. In Vitro Toxicology 4, 133-144.

Berthod, A., Tomer, S., Dorsey, J.G., 2001. Polyoxyethylene alkyl ether non-ionic surfactants: physicochemical properties and use for cholesterol determination in food. Talanta 55, 69-83.

Bielawski, J., 1990. Two types of haemolytic activity of detergents. Biochimica et Biophysica Acta 1035, 214-217.

Bogaerts, P., Bohatier, J., Bonnemoy, F., 2001. Use of the ciliated protozoan Tetrahymena pyriformis for the assessment of toxicity and quantitative structure-activity relationships of xenobiotics: comparison with the microtox test. Ecotoxicology and Environmental Safety 49, 293-301

Casalou, C., Cyrne, L., Rosa, M.R., Soares, H., 2001. Microtubule cytoskeleton perturbation induced by taxol and colchicine affects chaperonin containing TCP-1 (CCT) subunit gene expression in Tetrahymena cells. Biochimica et Biophysica Acta 1522, 9-21.

Cooper, J.A., 1991. The role of actin polimerization in cell motility. Annual Review of Physiology 53, 585-605.

Darcy, P., Kelly, J.P., Leonard, B.E., Henry, J.A., 2002. The effect of lofepramine and other related agents on the motility of Tetrahymena pyriformis. Toxicology Letters 128, 207-214.

Darvas, Z., Madarász, B., László, V., 1999. Study of histamine effects on phagocytosis and enzyme secretion of Tetrahymena pyriformis. Acta Biologica Hungarica 50, 325-334.

Dias, N., Nicolau, A., Lima, N., Carvalho, G.S., Mota, M., 1998. The use of immunocytochemical methods for toxicity assessement in Tetrahymena pyriformis. Cuadernos de Investigacion Biológica (Bilbao) 20, 75-78.

Dias, N., Nicolau, A., Carvalho, G.S., Mota, M., Lima, N., 1999. Miniaturization and application of the MTT assay to evaluate metabolic activity of protozoa in the presence of toxicants. Journal of Basic Microbiology 392, 103-108.

Dias, N., Lima, N., 2002. A comparative study using a fluorescencebased and a direct-count assay to determine cytotoxicity in Tetrahymena pyriformis. Research in Microbiology 153, 313-322.

Dryl, S., Mehr, K., 1976. Physiological and toxic effects of detergents on Paramecium caudatum. Acta Protozoologica 15, 501-513.

Fenchel, T., 1980. Suspension feeding in ciliated protozoa: functional response and particle size selection. Microbiology and Ecology 6, 111.

Galembeck, E., Alonso, A., Meirelles, N.C., 1998. Effects of polyoxyethylene chain length on erytrocyte hemolysis induced by poly [oxyethylene (n) nonylphenol] non-ionic surfactants. Chemico-Biological Interactions 113, 91-103.

Gräf, W., Gräf, H., Wenz, M., 1998/99. Tetrahymena pyriformis in the ciliate mobility test. Validation and description of a testing procedure for the registration of harmful substances in the air as well as the effects of cigarette smoke on the human respiratory ciliated epithelium. Zentralblatt für Hygiene und Umweltmedizin 201, 451572.

Grant, R.L., Yao, C., Gabaldon, D., Acosta, D., 1992. Evaluation of surfactant cytotoxicity potential by primary cultures of ocular tissues: I. Characterization of rabbit corneal epithelial cells and initial injury and delayed toxicity studies. Toxicology 76, 153-176.

Gülden, M., 1993. In vitro toxicity screening using cultured rat skeletal muscle cells: I. Surfactants and mitochondrial poisons. Toxicology in Vitro 7, 25-34.

Gurtubay, J.I., Goñi, F.M., Gómez-Fernández, J.C., Otamendi, J.J., Macarulla, J.M., 1980. Triton X-100 solubilization of mitochondrial inner and outer membranes. Journal of Bioenergetics and Biomembranes 12, 47-70.

Helistö, P., Koorpela, T., 1998. Effects of detergents on activity of microbial lipases as measured by the nitrophenyl alkanoate esters method. Enzyme and Microbial Technology 23, 113-117.

Kovács, P., Csaba, G., 1998. Effect of ceramide-analogues on the actin cytoskeleton of Tetrahymena pyriformis GL. A confocal microscopic analysis. Acta Protozoologica 37, 201-208.

Kovács, P., Hegyesi, H., Köhidai, L., Nemes, P., Csaba, G., 1999. Effects of $\mathrm{C}_{2}$ ceramide on the inositol phospholipid metabolism (uptake of ${ }^{32} \mathrm{P},{ }^{3} \mathrm{H}$-serine and ${ }^{3} \mathrm{H}$-palmitic acid) and apoptosis-related morphological changes in Tetrahymena. Comparative Biochemistry and Physiology 122 (Part C), 215-224.

Larsen, J., Schultz, T.W., Rasmussen, L., Hooftman, R., Pauli, W., 1997. Progress in an ecotoxicological standard protocol with protozoa: results from a pilot ring test with Tetrahymena pyriformis. Chemosphere 35, 1023-1041.

Le Dû, A., Dive, D., Guerbet, M., Jouany, J.M., 1993. The protozoan biotest Colpidium campylum, a tool for toxicity detection and toxic interaction modelling. The Science of the Total Environment (Supplem) 809-815.

Le Maire, M., Champeil, P., Møller, J.V., 2000. Interaction of membrane proteins and lipids with solubilizing detergents. Biochimica et Biophysica Acta 1508, 86-111.

Madoni, P., Esteban, G., Gorbi, G., 1992. Acute toxicity of cadmium, copper, mercury and zinc to ciliates from activated sludge plants. Bulletin of Environmental Contamination and Toxicology 49, 900 905.

Madoni, P., Davoli, D., 1994. Acute toxicity of lead, chromium and other heavy metals to ciliates from activated sludge plants. Bulletin of Environmental Contamination and Toxicology 53, 420-425.

Martin, A., Clynes, M., 1993. Comparison of 5 microplate colorimetric assays for in vitro cytotoxicity testing and cell proliferation assays. Cytotechnology 11, 49-58.

Méténier, G., 1984. Actin in Tetrahymena paravorax: ultrastructural localization of HMM-binding filaments in glycerinated cells. Journal of Protozoology 31, 205-215.

Meyer, R.R., Boyd, C.R., Rein, D.C., Keller, S.J., 1971. Effects of ethidium bromide on growth and morphology of Tetrahymena pyriformis. Experimental Cell Research 70, 233-237.

Nalecz-Jawecki, G., Sawicki, J., 2002. The toxicity of tri-substitued benzenes to the protozoan ciliate Spirostomum ambiguum. Chemosphere 46, 333-337.

Nicolau, A., Mota, M., Lima, N., 1999. Physiological responses of Tetrahymena pyriformis to copper, zinc, cyclohexymide and Triton X-100. FEMS Microbiology Ecology 30, 209-216. 
Nicolau, A., Dias, N., Mota, M., Lima, N., 2001. Trends in the use of protozoa in the assessment of wastewater treatment. Research in Microbiology 152, 621-630.

Nilsson, J.R., 1974. Effects of DMSO on vacuole formation, contractile vacuole function, and nuclear division in Tetrahymena pyriformis GL. Journal of Cell Science 16, 39-47.

Nilsson, J.R., 1981. Effects of copper on phagocytosis in Tetrahymena. Protoplasma 109, 359-370.

Nilsson, J.R., 1999. Vanadate affects nuclear division and induces aberrantly-shaped cells during subsequentr cytokinesis in Tetrahymena. Journal of Eukaryotic Microbiology 46, 24-33.

Noever, D.A., Matsos, H.C., Cronise, R.J., Looger, L.L., Relwani, R.A., 1994. Computerized in vitro test for chemical toxicity based on Tetrahymena swimming patterns. Chemosphere 29, 1373-1384.

Olabarrieta, I., L’Azou, B., Yuric, J., Cambar, J., Cajaraville, M.P., 2001. In vitro effects of cadmium on two different animal cell models. Toxicology in Vitro 15, 511-517.

Preté, P.S.C., Gomes, K., Malheiros, S.V.P., Meirelles, N.C., De Paula, E., 2002. Solubilization of human erythrocyte membranes by non-ionic surfactants of the polyoxyethylene alkyl ethers series. Biophysical Chemistry 97, 45-54.

Sauvant, M.P., Pepin, D., Bohatier, J., Groliere, C.A., Veyre, A., 1994. Comparative study of two in vitro models (L-929 fibroblasts and Tetrahymena pyriformis GL) for the cytotoxicological evaluation of packaged water. The Science of Total Environment 156, 159-167.

Sauvant, M.P., Pepin, D., Piccinni, E., 1999. Tetrahymena pyriformis: a tool for toxicological studies. A review. Chemosphere 38, 16311669.

Sauvant, M.P., Pepin, D., Bohatier, J., Groliere, C.A., 2000. Effects of chelators on the acute toxicity and bioavailability of aluminium to Tetrahymena pyriformis. Aquatic Toxicology 47, 259-275.
Schäfer, H., Hettler, H., Fritsche, U., Pitzen, G., Röderer, G., Wenzel, A., 1994. Biotests using unicellular algae and ciliates for predicting log-term effects of toxicants. Ecotoxicology and Environmental Safety $27,64-81$.

Schafer, D.A., Welch, M., Machesky, L.M., Bridgman, P.C., Meyer, S.M., Cooper, J.A., 1998. Visualization and molecular analysis of actin assembly in living cells. The Journal of Cell Biology 143, 1919-1930.

Stefanidou, M.E., Georgiou, M., Maravelias, C., Koutselinis, A., 1990. The effects of morphine, cocaine, amphetamine and hashish on the phagocytosis of the protozoon Tetrahymena pyriformis strain W. Toxicology in Vitro 4, 779-781.

Stefanidou, M., Alevisopoulos, G., Maravelias, C., Loutsidis, C., Koutselinis, A., 1999. Phagocytosis of the protozoon Tetrahymena pyriformis as an endpoint in the estimation of cocaine salt and cocaine freebase toxicity. Addiction Biology 4, 449-452.

Stowe, R.P., Koenig, D.W., Mishra, S.K., Pierson, D.L., 1995. Nondestructive and continuous spectrophotometric measurment of cell respiration using a tetrazolium-formazan microemulsion. Journal of Microbiological Methods 22, 283-292.

Szydlowska, H., Zaporowska, E., Kuszlik-Jochym, K., Korohoda, W., Branny, J., 1978. Membranolytic activity of detergents as studies with cell viability tests. Folia Histochemica and Cytochemica 16, 69-78.

Trägner, D., Csordas, A., 1987. Biphasic interaction of triton detergents with the erythrocyte membrane. Biochemical Journal 244, 605-609.

Twagilimana, L., Bohatier, J., Groliere, C.A., Bonnemoy, F., Sargos, D., 1998. A new low-cost microbiotest with the protozoan Spirotomum teres: culture conditions and assessment of sensitivity of the ciliate to 14 pure chemicals. Ecotoxicology and Environmental Safety 41, 231-244.

Wu, C., Fry, C.H., Henry, J.A., 1997. Membrane toxicity of opioids measured by protozoan motility. Toxicology $117,35-44$. 